\title{
Getting Started in
}

Logit and Ordered

Logit Regression

(ver. 3.1 beta)

Oscar Torres-Reyna

\section{Data Consultant}

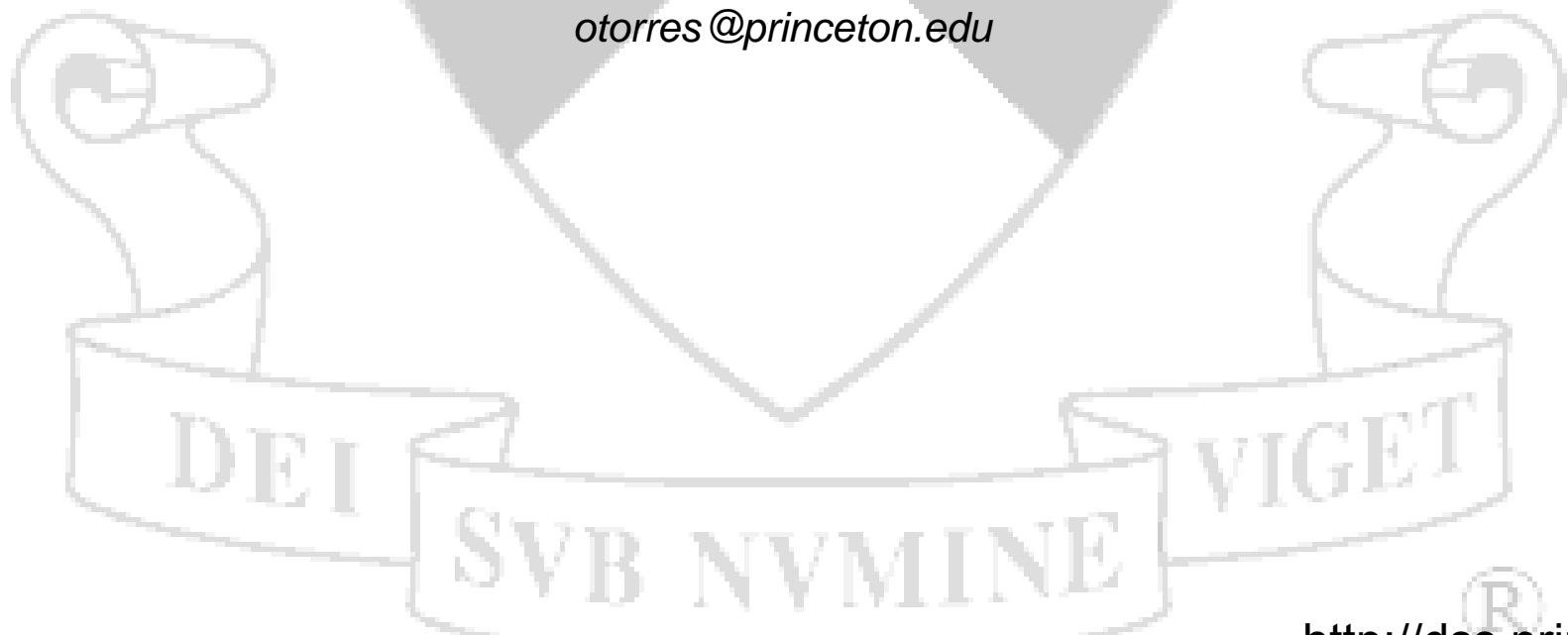

http://dss.princeton.edu/training/ 


\section{Logit model}

- Use logit models whenever your dependent variable is binary (also called dummy) which takes values 0 or 1 .

- Logit regression is a nonlinear regression model that forces the output (predicted values) to be either 0 or 1 .

- Logit models estimate the probability of your dependent variable to be $1(Y=1)$. This is the probability that some event happens. 


\section{Logit model}

From Stock \& Watson, key concept 9.3. The logit model is:

$$
\begin{aligned}
& \operatorname{Pr}\left(Y=1 \mid X 1, X 2, \ldots X_{k}\right)=F\left(\beta_{0}+\beta_{1} X 1+\beta_{2} X 2+\ldots+\beta_{K} X_{K}\right) \\
& \operatorname{Pr}\left(Y=1 \mid X 1, X 2, \ldots X_{k}\right)=\frac{1}{1+e^{-\left(\beta_{0}+\beta_{1} X 1+\beta_{2} X 2+\ldots+\beta_{K} X_{K}\right)}} \\
& \operatorname{Pr}\left(Y=1 \mid X 1, X 2, \ldots X_{k}\right)=\frac{1}{1+\left(\frac{1}{e^{\left(\beta_{0}+\beta_{1} X 1+\beta_{2} X 2+\ldots+\beta_{K} X_{K}\right)}}\right)}
\end{aligned}
$$

Logit and probit models are basically the same, the difference is in the distribution:

- Logit - Cumulative standard logistic distribution $(F)$

- Probit - Cumulative standard normal distribution (Ф)

Both models provide similar results. 
In Stata you run the model as follows:

\section{Logit model}

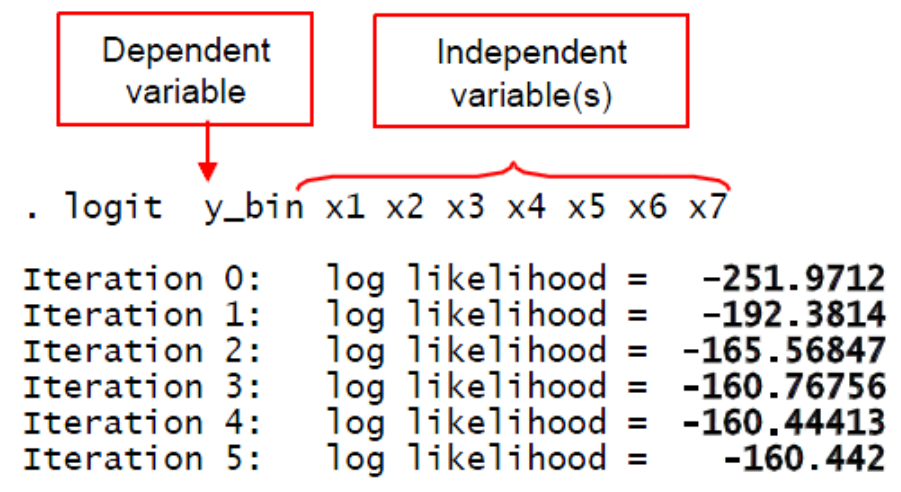

Logistic regression

Log likelihood $=\quad \mathbf{- 1 6 0 . 4 4 2}$
Number of obs LR chi2(7)

Prob > chi2

Pseudo R2
$=$ $=$

$=$

$=$
It tests whether the

combined effect, of all the variables in the model, is different from zero. If, for example, $<0.05$ then the model have some relevant explanatory power, which does not mean it is well specified or at all correct.
Logit coefficients are in log-odds units and cannot be read as regular OLS coefficients. To interpret you need to estimate the predicted probabilities of $Y=1$ (see next page)
Test the hypothesis that each coefficient is different from 0 . To reject this, the t-value has to be higher than 1.96 (for a $95 \%$ confidence). If this is the case then you can say that the variable has a significant influence on your dependent variable (y). The higher the $z$ the higher the relevance of the variable.
Two-tail p-values test the hypothesis that each coefficient is different from 0 . To reject this, the $p$-value has to be lower than 0.05 ( $95 \%$, you could choose also an alpha of 0.10 ), if this is the case then you can say that the variable has a significant influence on your dependent variable (y) 
After running the model:

\section{Logit: predicted probabilities}

logit $y \_b i n \times 1 \times 2 \times 3 \times 4 \times 5 \times 6 \times 7$

Type

predict y_bin_hat $/{ }^{*}$ These are the predicted probabilities of $Y=1$ * / Here are the estimations for the first five cases, type:

browse y_bin $\times 1 \times 2 \times 3 \times 4 \times 5 \times 6 \times 7$ y_bin_hat

Predicted probabilities

\begin{tabular}{|r|r|r|r|r|r|r|r|r}
\hline y_bin & $\times 1$ & $\times 2$ & $\times 3$ & $\times 4$ & $\times 5$ & $\times 6$ & $\times 7$ & y_bin_hat \\
\hline 1 & 3 & .2779036 & -1.107956 & .2825536 & -2.971267 & .554832 & -.5820704 & .7841014 \\
\hline 0 & 3 & .3206847 & -.94872 & .4925385 & -1.371243 & -.0959275 & -.6641465 & .6678266 \\
\hline 0 & 3 & .3634657 & -.789484 & .7025234 & .2287798 & -.7466869 & -.7462227 & .5267279 \\
\hline 1 & 3 & .246144 & -.885533 & -.0943909 & -.3198499 & -.3573879 & .0628607 & .9274359 \\
\hline 1 & 3 & .424623 & -.7297683 & .9461306 & .1230506 & -.0358964 & .095743 & .9439594 \\
\hline 1 & 3 & .4772141 & -.723246 & 1.02968 & .1175985 & -.0022627 & .0965806 & .9448991 \\
\hline
\end{tabular}

To estimate the probability of $Y=1$ for the first row, replace the values of $X$ into the logit regression equation. For the first case, given the values of $X$ there is $79 \%$ probability that $Y=1$ :

$$
\operatorname{Pr}\left(Y=1 \mid X_{1}, X_{2}, \ldots X_{7}\right)=\frac{1}{1+\left(\frac{1}{e^{\left(1.58+0.26 X_{1}-.25 X_{2}+0.11 X_{3}+0.36 X_{4}-0.31 X_{5}-0.13 X_{6}+3.20 X_{7}\right)}}\right)}=0.7841014
$$




\section{Logit: Odds ratio}

You can request odds ratio rather than logit coefficients by adding the option or (after comma)

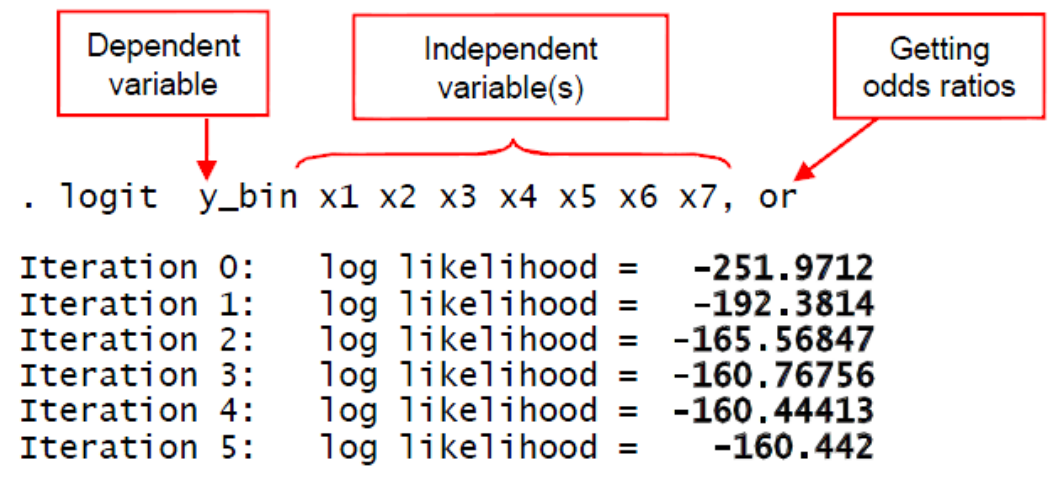

Logistic regression

Log Tikelihood $=\quad-160.442$
Number of obs= LR chi2(7) Prob > chi2 Pseudo R2
It tests whether the

combined effect, of all the variables in the model, is different from zero. If, for example, $<0.05$ then the model have some relevant explanatory power, which does not mean it is well specified or at all correct.

\begin{tabular}{|c|c|c|c|c|c|c|}
\hline y_bin & odds Ratio & std. Err. & $z$ & $\mathrm{P}>|z|$ & [95\% Conf. & Interva1] \\
\hline $\begin{array}{l}\times 1 \\
\times 2 \\
\times 3 \\
\times 4 \\
\times 5 \\
\times 6 \\
\times 7\end{array}$ & $\begin{array}{l}1.309653 \\
.7787547 \\
1.121923 \\
1.440474 \\
.7311612 \\
.8727118 \\
24.70453\end{array}$ & $\begin{array}{r}.2304567 \\
.1136862 \\
.1667381 \\
.2210176 \\
.1073196 \\
.1367534 \\
8.971405\end{array}$ & $\begin{array}{r}1.53 \\
-1.71 \\
0.77 \\
2.38 \\
-2.13 \\
-0.87 \\
8.83\end{array}$ & $\begin{array}{l}0.125 \\
0.087 \\
0.439 \\
0.017 \\
0.033 \\
0.385 \\
0.000\end{array}$ & $\begin{array}{r}.9276246 \\
.5849765 \\
.8384153 \\
1.066356 \\
.5483705 \\
.6419307 \\
12.12451\end{array}$ & $\begin{array}{l}1.849014 \\
1.036724 \\
1.501299 \\
1.945847 \\
.9748823 \\
1.186461 \\
50.33718\end{array}$ \\
\hline
\end{tabular}

Note: 1 failupe and 1 success completely determined.

They represent the odds of $Y=1$ when $X$ increases by 1 unit. These are the $\exp ($ logit coeff).

If the $O R>1$ then the odds of $Y=1$ increases

If the $O R<1$ then the odds of $Y=1$ decreases

Look at the sign of the logit coefficients
Test the hypothesis that each coefficient is different from 1 . To reject this, the t-value has to be higher than 1.96 (for a $95 \%$ confidence). If this is the case then you can say that the variable has a significant influence on your dependent variable $(y)$. The higher the $z$ the higher the relevance of the variable.
Two-tail p-values test the hypothesis that each coefficient is different from 1. To reject this, the $p$-value has to be lower than 0.05 (95\%, you could choose also an alpha of 0.10 ), if this is the case then you can say that the variable has a significant influence on your dependent variable $(y)$ 


\section{Predicted probabilities and marginal effects}

For the latest procedure see the following document:

http://dss.princeton.edu/training/Margins.pdf

The procedure using prvalue in the following pages does not work with Stata 13. 


\section{Ordinal logit}

When a dependent variable has more than two categories and the values of each category have a meaningful sequential order where a value is indeed 'higher' than the previous one, then you can use ordinal logit.

Here is an example of the type of variable:

\begin{tabular}{|c|c|c|c|}
\hline $\begin{array}{c}\text { Agr eement } \\
\text { I evel }\end{array}$ & Freq. & Percent & Cum \\
\hline Di sagree & 190 & 38. 78 & 38. 78 \\
\hline Neut ral & 104 & 21.22 & 60.00 \\
\hline Agree & 196 & 40. 00 & 100.00 \\
\hline Tot al & 490 & 100. 00 & \\
\hline
\end{tabular}




\section{Ordinal logit: the setup}

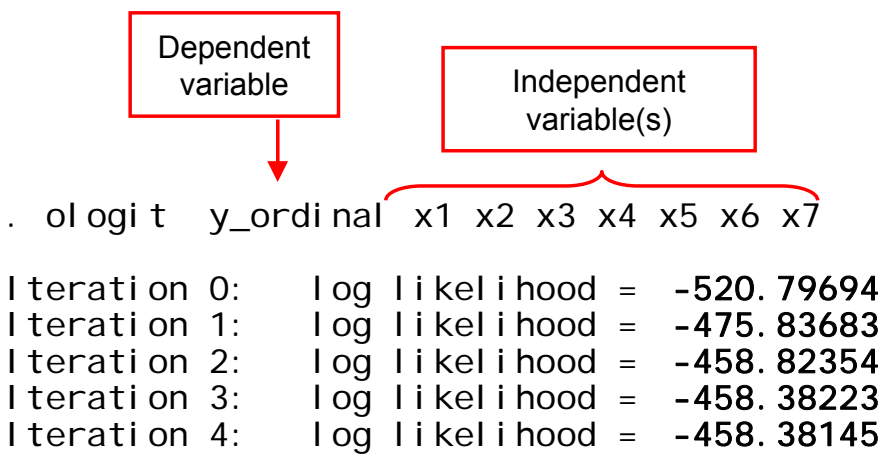

Ordered l ogistic regression

Log I i kel i hood $=-458.38145$

$\begin{array}{llr}\text { Number of obs } & = & 490 \\ \text { LR chi 2( 7) } & = & 124.83 \\ \text { Prob > chi } 2 & = & 0.0000 \\ \text { Pseudo R2 } & = & 0.1198\end{array}$

If this number is $<0.05$ then your model is ok. This is a test to see whether all the coefficients in the model are different than zero.

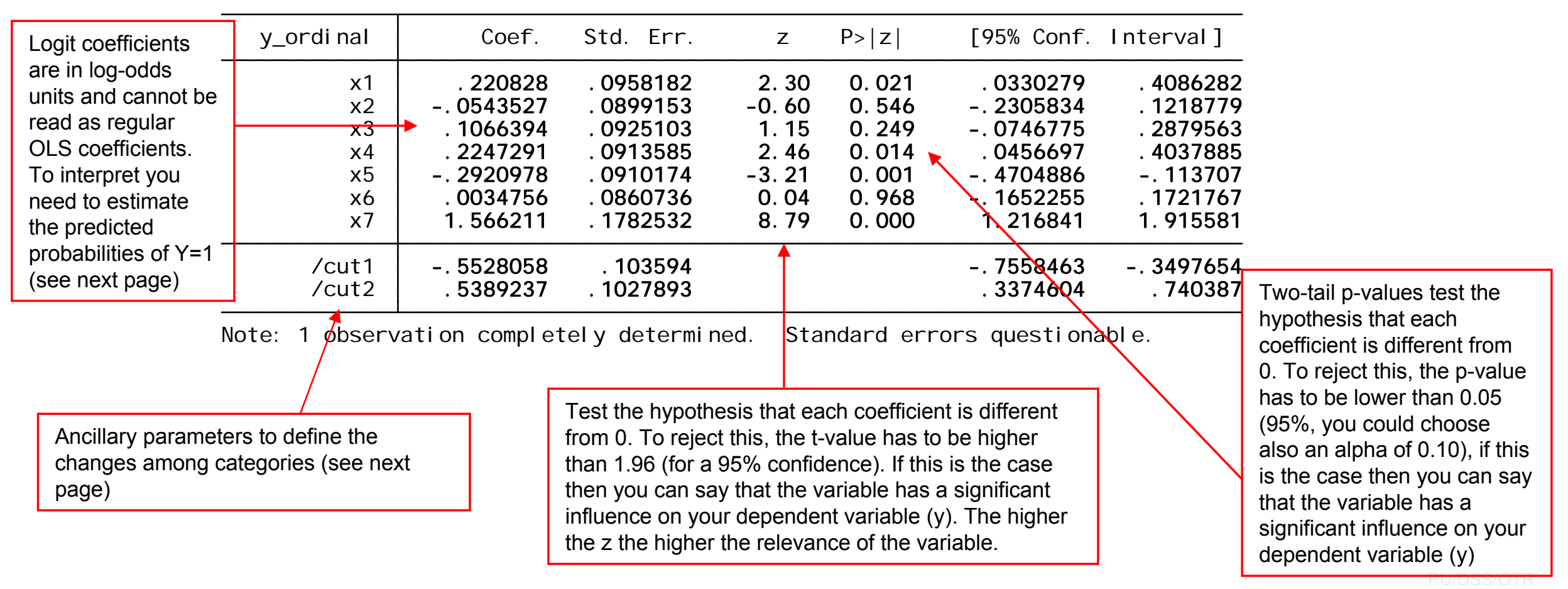




\section{Ordinal logit: predicted probabilities}

Following Hamilton, 2006, p.279, ologit estimates a score, S, as a linear function of the X's:

$$
S=0.22 X_{1}-0.05 X_{2}+0.11 X_{3}+0.22 X_{4}-0.29 X_{5}+0.003 X_{6}+1.57 X_{7}
$$

Predicted probabilities are estimated as:

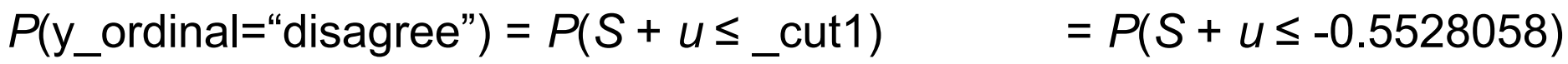

$P\left(y_{-}\right.$ordinal="neutral" $) \quad=P\left(\right.$ ccut $1<S+u \leq \_$cut 2$)=P(-0.5528058<S+u \leq 0.5389237)$

$P\left(y_{-}\right.$ordinal $=$"agree" $) \quad=P\left(\_\right.$cut $\left.2<S+u\right) \quad=P(0.5389237<S+u)$

To estimate predicted probabilities type predict right after ologit model. Unlike logit, this time you need to specify the predictions for all categories in the ordinal variable (y_ordinal), type:

predict disagree neutral agree 


\section{Ordinal logit: predicted probabilities}

To read these probabilities, as an example, type

browse country disagree neutral agree if year==1999

In 1999 there is a $62 \%$ probability of 'agreement' in Australia compared to $58 \%$ probability in 'disagreement' in Brazil while Denmark seems to be quite undecided.

\begin{tabular}{|r|r|r|c}
\hline \multicolumn{1}{|c|}{ country } & disagree & neutral & \multicolumn{1}{c|}{ agree } \\
\hline Australia & .1700809 & .2090298 & .6208892 \\
\hline Austria & .17576 & .2127421 & .6114978 \\
\hline Belgium & .3058564 & .2617683 & .4323753 \\
\hline Botswana & .1215602 & .1703741 & .7080657 \\
\hline Brazil & .5808533 & .2241725 & .1949743 \\
\hline Bulgaria & .3134856 & .2628762 & .4236383 \\
\hline Burundi & .5940011 & .2193996 & .1865993 \\
\hline Canada & .1627286 & .2039865 & .6332849 \\
\hline Chile & .1998139 & .2267881 & .5733979 \\
\hline Denmark & .3604209 & .2663039 & .3732751
\end{tabular}




\section{Predicted probabilities and marginal effects}

For the latest procedure see the following document:

http://dss.princeton.edu/training/Margins.pdf

The procedure using prvalue in the following pages does not work with Stata 13. 


\section{Predicted probabilities: using prvalue}

After runing ologit (or logit) you can use the command prvalue to estimate the probabilities for each event.

Prvalue is a user-written command, if you do not have it type findit spost, select spost9_ado from http://WWw. indiana.edu/ jslsoc/stata and click on "(click here to install)"

If you type prvalue without any option you will get the probabilities for each category when all independent values are set to their mean values.

prval ue

ol ogit: Predictions for y_or di nal
Confi dence i ntervals by del ta method

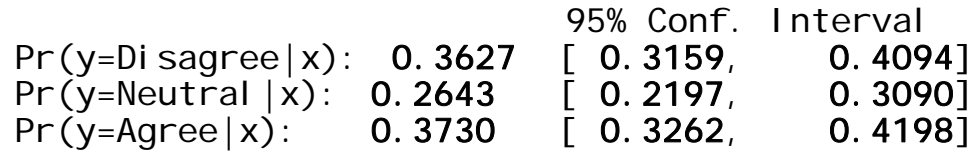

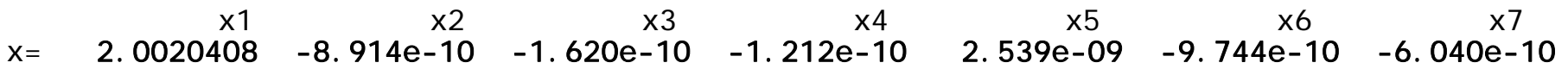

You can also estimate probabilities for a particular profile (type help prvalue for more details).

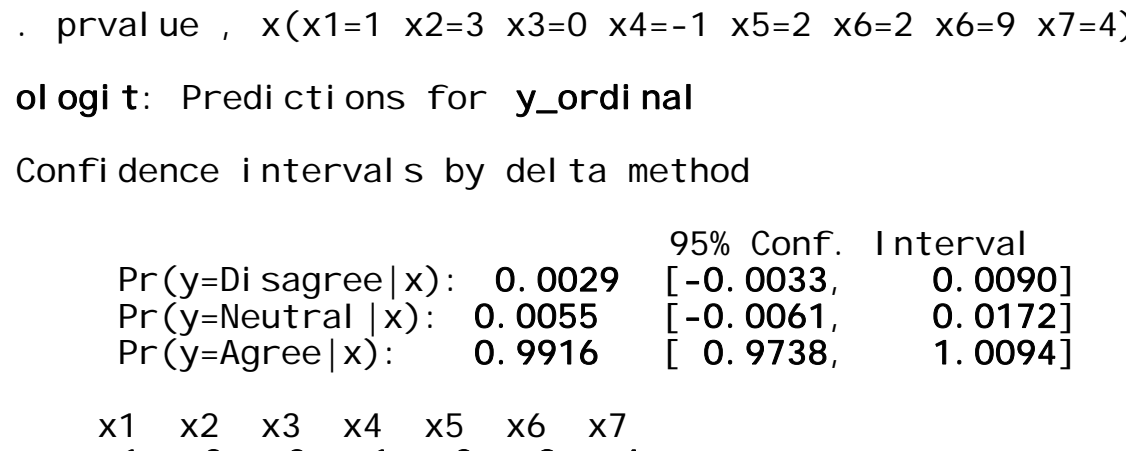




\section{Predicted probabilities: using prvalue}

If you want to estimate the impact on the probability by changing values you can use the options save and dif (type help prvalue for more details)

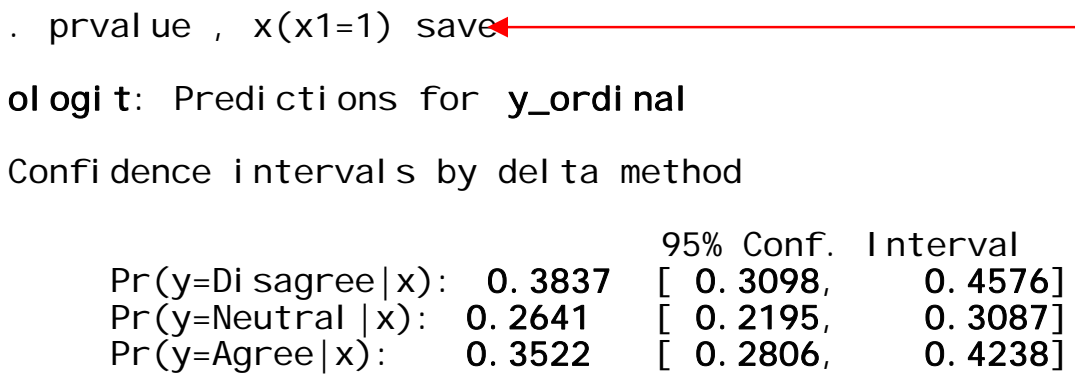

Probabilities when $\mathrm{x} 1=1$ and all other independent variables are held at their mean values. Notice the save option.
Probabilities when $\times 1=2$ and all other independent variables are held at their mean values. Notice the dif option.

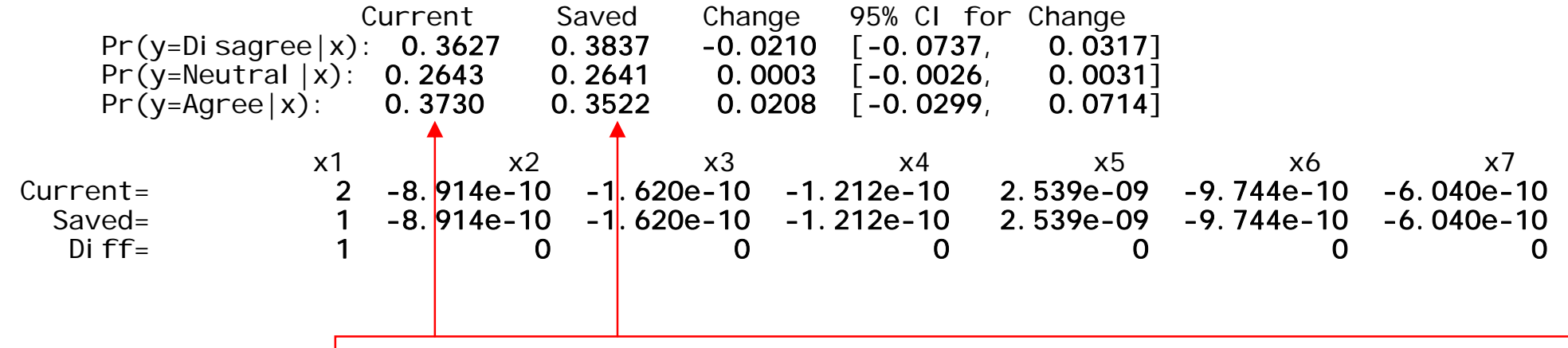

NOTE: You can do the same with logit or probit models
Here you can see the impact of $x 1$ when it changes from 1 to 2 .

For example, the probability of $y=A$ gree goes from $35 \%$ to $37 \%$ when $\mathrm{x} 1$ changes from 1 to 2 (and all other independent variables are held at their constant mean values. 


\section{Useful links I Recommended books}

- DSS Online Training Section http://dss.princeton.edu/training/

- UCLA Resources to learn and use STATA http://www.ats.ucla.edu/stat/stata/

- DSS help-sheets for STATA http://dss/online help/stats packages/stata/stata.htm

- Introduction to Stata (PDF), Christopher F. Baum, Boston College, USA. "A 67-page description of Stata, its key features and benefits, and other useful information."

http://fmwww.bc.edu/GStat/docs/Statalntro.pdf

- STATA FAQ website http://stata.com/support/faqs/

- Princeton DSS Libguides http://libguides.princeton.edu/dss

\section{Books}

- Introduction to econometrics / James H. Stock, Mark W. Watson. 2nd ed., Boston: Pearson Addison Wesley, 2007.

- Data analysis using regression and multilevel/hierarchical models / Andrew Gelman, Jennifer Hill. Cambridge ; New York : Cambridge University Press, 2007.

- Econometric analysis / William H. Greene. 6th ed., Upper Saddle River, N.J. : Prentice Hall, 2008.

- Designing Social Inquiry: Scientific Inference in Qualitative Research / Gary King, Robert O. Keohane, Sidney Verba, Princeton University Press, 1994.

- Unifying Political Methodology: The Likelihood Theory of Statistical Inference / Gary King, Cambridge University Press, 1989

- Statistical Analysis: an interdisciplinary introduction to univariate \& multivariate methods / Sam Kachigan, New York : Radius Press, c1986

- Statistics with Stata (updated for version 9) / Lawrence Hamilton, Thomson Books/Cole, 2006 